\title{
Evaluation of the Knowledge, Attitude and Practice of Self-Medication among First-Year Medical Students
}

\author{
Henry James Shailendra S. Handu Khalid A.J. Al Khaja Sameer Otoom \\ Reginald P. Sequeira
}

Department of Pharmacology and Therapeutics, College of Medicine and Medical Sciences, Arabian Gulf University, Manama, Kingdom of Bahrain

\section{Key Words}

Self-medication $\cdot$ Medical students $\cdot$ Self-care $\cdot$ Health policy

\begin{abstract}
Objective: This study was undertaken to determine the knowledge, attitude and practice of self-medication among first-year medical students of the Arabian Gulf University, Bahrain. Subjects and Methods: This was an anonymous, questionnaire-based, descriptive study. A prevalidated questionnaire, containing open-ended and close-ended questions, was administered to the subjects. Data were analyzed using SPSS version 12 and the results expressed as counts and percentages. Results: Out of the 134 respondents, $43(32.1 \%)$ were males and $91(67.9 \%)$ were females; their mean age in years \pm SD was $18.01 \pm 0.78$. The respondents' knowledge about appropriate self-medication was poor, but knowledge of the benefits and risks of self-medication was adequate. The respondents found self-medication to be time-saving, economical, convenient and providing quick relief in common illnesses. Important disadvantages of selfmedication mentioned were the risk of making a wrong diagnosis, inappropriate drug use and adverse effects. The majority $(76.9 \%)$ of the respondents had a positive attitude favoring self-medication. Self-medication was
\end{abstract}

practiced by $44.8 \%$ of the subjects. The most common indications for self-medication were to relieve the symptoms of headache $(70.9 \%)$, cough, cold and sore throat $(53.7 \%)$, stomachache $(32.8 \%)$ and fever $(29.9 \%)$. Analgesics $(81.3 \%)$ were the most common drugs used for self-medication. The practice of self-medication was appropriate in only $14.2 \%$ of cases. Conclusion: Knowledge about appropriate self-medication was poor, attitude towards self-medication was positive, and the practice of self-medication was common and often inappropriate.

Copyright (C) 2006 S. Karger AG, Basel

\section{Introduction}

It is common for people to feel unwell, and human beings have an inherent tendency to use herbs, potions, medications, etc. for treating themselves. Every day people throughout the world act on their own for their health; they practice self-care. In some instances, they do so through self-medication, which is now increasingly being considered as a component of self-care [1]. Some governments are increasingly encouraging self-care of minor illnesses, including self-medication [2]. Encouragement of self-care is seen as giving patients every opportunity to take responsibility and build confidence in their ability to manage their own health. Patient empowerment is viewed

\section{KARGER}

Fax +4161306 1234 E-Mail karger@karger.ch www.karger.com
(C) 2006 S. Karger AG, Basel

$1011-7571 / 06 / 0154-0270 \$ 23.50 / 0$

Accessible online at:

www.karger.com/mpp
Dr. Henry James

Department of Pharmacology and Therapeutics

College of Medicine and Medical Sciences

Arabian Gulf University, PO Box 22979, Manama (Kingdom of Bahrain)

Tel. +973 1723 9841, Fax +973 1727 1090, E-Mail DrHenryJames@hotmail.com 
as a positive step in the development of the relationship between patient and healthcare provider and is considered as an important health policy concept $[1,3]$.

Self-medication is defined as the use of medication, whether modern or traditional, for self-treatment. Studies done on self-medication reveal that it is a fairly common practice, especially in economically deprived communities. It is a growing trend of 'self-care' which has its positive and negative aspects [1, 4].

In several studies it has been found that inappropriate self-medication results in wastage of resources, increases resistance of pathogens and generally entails serious health hazards such as adverse drug reactions, prolonged suffering and drug dependence $[1,5,6]$. On the other hand, if done appropriately, self-medication can readily relieve acute medical problems, can save the time spent in waiting to see a doctor, may be economical and can even save lives in acute conditions. It is now accepted that self-care in the form of responsible self-medication can be beneficial for patients, healthcare providers, the pharmaceutical industry and governments [1]. The World Health Organization (WHO) has also pointed out that responsible self-medication can help prevent and treat ailments that do not require medical consultation and provides a cheaper alternative for treating common illnesses $[7,8]$. However, it is also recognized that self-medication must be accompanied by appropriate health information.

Studies on self-medication show that it is influenced by many factors, such as education, family, society, law, availability of drugs and exposure to advertisements [9, 10]. A high level of education and professional status have been mentioned as predictive factors for self-medication [11]. The reasons for self-medication mentioned in the literature are mild illness, previous experience of treating similar illness, economic considerations and a lack of availability of healthcare personnel. The most common medications used for self-medication are analgesics and antimicrobials [1, 12].

Self-medication is an area where governments and health authorities need to ensure that it is done in a responsible manner, ensuring that safe drugs are made available over the counter and the consumer is given adequate information about the use of drugs and when to consult a doctor $[1,3,7]$. Unlike other aspects of self-care, self-medication involves the use of drugs, and drugs have the potential to do good as well as cause harm. In this context, the pharmacist has an important role $[1,3]$.

There is a paucity of studies on self-medication among medical students. Medical students may differ from the general population because they are exposed to knowledge about diseases and drugs. The present study was undertaken to determine the knowledge, attitude and practice of self-medication among first-year medical students of the Arabian Gulf University, Bahrain.

\section{Subjects and Methods}

This study was an anonymous, questionnaire-based survey approved by the Research and Ethics Committee of the College of Medicine and Medical Sciences, Arabian Gulf University, Bahrain. It was undertaken in November 2004.

A self-developed, prevalidated questionnaire consisting of both open-ended and close-ended items was used. The study population comprised first-year medical students of the Arabian Gulf University, Bahrain. These were young men and women, all Arab nationals, who had recently joined the medical college. All first-year medical students who were willing to participate in the study were enrolled. A briefing was given about the nature of the study, and the procedure of completing the questionnaire was explained. Consenting participants anonymously completed the questionnaire in the classroom.

For the purpose of the study, certain operational terms were defined. Self-medication was defined as the use of over-the-counter or prescription drugs, whether modern or traditional, for self-treatment, without prior consultation with a doctor. A doctor was defined as any person who is medically qualified to prescribe medications. It included practitioners of modern scientific medicine as well as practitioners of other healthcare systems. Medication was defined as any substance used for treatment or prevention of disease. It included modern scientific medications as well as medications from other healthcare systems.

The survey was descriptive and data were summarized as counts and percentages. SPSS version 12 was used for data analysis. The $\chi^{2}$ test was used to test the difference between proportions. A $p$ value of less than 0.05 was considered significant. Some of the questions had multiple options to choose from, therefore the sum total of percentages is not always $100 \%$.

\section{Results}

On the day when the questionnaire was administered, 134 students out of 153 were present. All the students ( $\mathrm{n}=134)$ responded to the questionnaire, of whom 43 $(32.1 \%)$ were males and $91(67.9 \%)$ were females. Their mean age in years \pm SD was $18.01 \pm 0.78$ (range from 17 to 21 years). The nationality of the subjects is shown in table 1 .

\section{Knowledge}

The respondents perceived several advantages and disadvantages of self-medication (table 2). The most important advantages were saving time (45.5\%), doing away 
with the need to go to a doctor for a minor illness (25.4\%), being economical (14.9\%) and providing quick relief (11.9\%). The most serious disadvantages of self-medication as perceived by the respondents were the risk of adverse drug reactions $(32.8 \%)$ and the risk of using inappropriate drugs $(31.3 \%)$.

\section{Attitude}

The majority (76.9\%) of the respondents had a positive attitude towards self-medication and favored self-medication saying that it was acceptable, while $14.9 \%$ felt it was unacceptable.

When asked about the influence of medical knowledge on their attitude towards self-medication, $64.2 \%$ felt it would make them more careful, $43.3 \%$ would prefer seeking a prescription, $24.6 \%$ were afraid of adverse drug reactions and $22.4 \%$ felt they would discourage self-medication. On the other hand, some respondents were made more confident $(24.6 \%)$ and some would advocate selfmedication (13.4\%). There was no change in $13.4 \%$ of the respondents.

\section{Practice}

Of the 134 respondents, $60(44.8 \%)$ practiced selfmedication, which included $45.1 \%$ of females and $44.2 \%$ of males. The remaining 74 (55.2\%) respondents preferred consulting a doctor by going to a private clinic (33.6\%), a primary healthcare center $(31.3 \%)$, a doctorfriend $(28.4 \%)$ or a referral hospital $(20.1 \%)$.

The most important reasons quoted for not consulting a doctor were previous experience (45.5\%), mild illness $(40.3 \%)$ and shortage of time (32.1\%); rarely, it was advice from a friend $(5.2 \%)$ and nonavailability of a doctor $(4.5 \%)$. There were several indications for self-medication (table 3); the most common indications were headache and cough, cold and sore throat. Stomachache was mentioned by many respondents, of whom 37 (84.1\%) were females.

The most common drug group used for self-medication was analgesics $(81.3 \%)$, in which paracetamol was always used, and, in some cases, nonsteroidal anti-inflammatory drugs were also used. Other drugs employed in self-medication are shown in figure 1. It may be noted here that all users of antispasmodics were female subjects. In most instances, drugs were obtained from private pharmacies $(85.8 \%)$, friends $(16.4 \%)$ or the supermarket (14.9\%).

The majority of the participants $(n=96,71.6 \%)$ read the package insert. Of these 73 were females, representing $80 \%$ of the female subjects, and 23 were males, represent-
Table 1. Nationality of the respondents

\begin{tabular}{lccc}
\hline Nationality & Males & Females & Total \\
\hline Saudi Arabia & 23 & 42 & $65(48.5 \%)$ \\
Bahrain & 10 & 26 & $36(26.9 \%)$ \\
Kuwait & 9 & 14 & $23(17.2 \%)$ \\
Oman & 1 & 7 & $8(6 \%)$ \\
United Arab Emirates & 0 & 1 & $1(0.7 \%)$ \\
Lebanon & 0 & 1 & $1(0.7 \%)$ \\
\hline Total & $43(32.1 \%)$ & $91(67.9 \%)$ & $134(100 \%)$ \\
\hline
\end{tabular}

Table 2. Reasons in favor of (advantages) and against (disadvantages) self-medication

\begin{tabular}{ll}
\hline Reasons stated by the respondents & Respondents, \% \\
\hline Reasons in favor of self-medication & \\
Time-saving & 45.5 \\
No need to visit doctor for minor illness & 25.4 \\
Economical & 14.9 \\
Quick relief & 11.9 \\
Learning opportunity & 7.5 \\
Ease and convenience & 7.5 \\
Crowd avoidance & 2.2 \\
\hline Reasons against self-medication & \\
Risk of adverse drug reactions & 32.8 \\
Risk of using wrong drugs & 31.3 \\
Risk of wrong use of drugs & 17.9 \\
Risk of missing the diagnosis & 6 \\
Risk of drug dependence & 1.5 \\
\hline
\end{tabular}

Table 3. Indications for self-medication

\begin{tabular}{ll}
\hline Indications & Respondents, \% \\
\hline Headache & 70.9 \\
Cough, cold, sore throat & 53.7 \\
Stomachache & 32.8 \\
Fever & 29.9 \\
Menstrual symptoms & 8.2 \\
Vomiting & 3.7 \\
Skin symptoms & 2.2 \\
Eye symptoms & 2.2 \\
Ear symptoms & 0.7 \\
Diarrhea & 0.7 \\
\hline
\end{tabular}




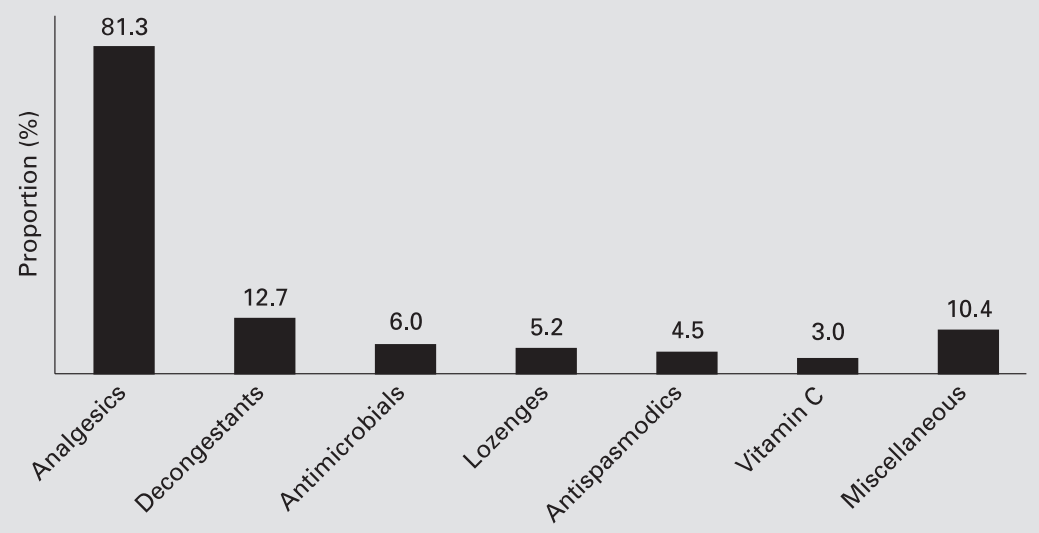

Fig. 1. Drugs employed in self-medication.

ing 53\% of the male subjects. This difference between males and females was statistically significant $(p<0.0037)$. Of those who did not read the package insert $(n=31$, $23.1 \%), 15$ were females and 16 were males. The remaining 7 did not answer this question.

The data were further evaluated for appropriateness of drug usage, based on information provided about the drug dose, dosage form, frequency of administration and duration of treatment. Self-medication was appropriate in only $14.2 \%$ of cases, while in $51.5 \%$ it was deemed inappropriate. In the remaining $34.3 \%$ cases data were not available.

\section{Discussion}

The study population in this survey consisted of firstyear medical students. They were all Arabs, most of them citizens of the countries of the Gulf Cooperation Council (table 1). These were therefore adolescents with shared sociocultural, ethnic and educational background who were beginning to be exposed to medical information.

\section{Knowledge}

The respondents had a fairly good knowledge of the advantages and disadvantages of self-medication. Many of them correctly perceived self-medication as time-saving and economical, doing away with the need to go to a doctor for minor illness and providing quick, easy and convenient relief. These perceptions are similar to those reported by the WHO that self-medication provides a cheaper and convenient alternative for treating common minor illnesses [7, 8]. These are important factors favoring self-medication and have been reported in other studies $[1,12]$. However, this could also mean that health services need to be improved so that treatment becomes more accessible and the patient's waiting time is minimized. Length of waiting time for medical consultation has been identified as one of the predictive factors for self-medication [11]. The most important deterrents for self-medication were fear of adverse drug reactions, risk of making a wrong diagnosis and risk of using a wrong drug (fear of the unknown), similar to an earlier study [1].

\section{Attitude}

The majority of the respondents had a positive attitude towards self-medication, saying that it was acceptable. It is however arguable whether students just enrolled in a medical program may have had the knowledge of diseases and drugs different from the matched general public. This has implications, because wrong or inadequate information and misplaced self-confidence may encourage inappropriate self-medication and expose the subjects to potential health risks.

In general, the respondents felt that medical knowledge was making them more cautious about self-medication and many would prefer to seek a prescription. Some were afraid of adverse drug reactions, while others felt they would discourage self-medication. This suggests that public health education and increased awareness are important for making self-medication safe and useful. This has also been noted by the WHO [7] and by Hughes [13]. Recently, we have shown that increasing medical knowl- 
edge affects the prescribing behavior of medical students [14]. It would be interesting to investigate further whether increasing medical knowledge also affects the knowledge, attitude and practice of self-medication among medical students.

\section{Practice}

In this study, almost half of the respondents practiced self-medication. Studies on self-medication have reported various prevalence figures, ranging from $26.2 \%$ [11] to as high as $92 \%$ [15]. Although a similar proportion of males and females practiced self-medication, there were gender-based differences in the practice of self-medication. Females practiced self-medication more diligently than males and a greater proportion of them reported reading the package inserts. Studies have shown genderbased differences in communication and health-seeking behavior [16, 17]. Differences in self-medication between male and female highschool students have also been documented [15].

Those with a previous experience and with mild illness were more likely to practice self-medication. This has implications, because many diseases have similar symptoms, and a person using previous experience may be exposed to the dangers of misdiagnosis and consequently wrong treatment.

The commonest illnesses that led to self-medication in this study were usually self-limiting 'minor illnesses' that have been widely reported in studies on self-medication as the most common indications [1,12]. The majority of the 'stomachache' cases were females, and they were probably using this term for abdominal symptoms associated with the menstrual cycle. This is also supported by the fact that all subjects who used antispasmodics were females.

Analgesics have been reported to be the most commonly used group of drugs $[1,18]$. Our study also found similar results. Among the analgesics, paracetamol was the most commonly used drug. This correlates well with headache being the most common indication for selfmedication. Paracetamol is widely used for headache, fever and body aches and pains. The use of antimicrobials has been very limited in this study sample. The limited use of antimicrobials in this study may be because of the fact that the governments in the countries to which our subjects belong have strict regulatory policies about the prescription and over-the-counter sale of antimicrobials. Some studies have reported a higher use of antimicrobials when the subject was a healthcare person [18].
The finding that is most alarming is the high level of inappropriate use of medications. First-year medical students are beginning to be exposed to medical information and have a very limited medical knowledge. They are at a risk of misplaced self-confidence. Ignorance and misplaced self-confidence can lead to inappropriate self-medication and expose the subjects to all the risks associated with inappropriate use of medications [1].

\section{Conclusion}

This descriptive survey shows that the first-year medical students had a poor knowledge about appropriate self-medication while the knowledge of the benefits and risks was adequate. The attitude towards self-medication was positive. The practice of self-medication was common and, in most cases, inappropriate. It would be interesting to evaluate the changes in self-medication pattern while students progress through the medical school.

\section{Acknowledgement}

The authors would like to thank the first-year medical students of the Arabian Gulf University, Bahrain, for co-operating and making this study possible. 


\section{References}

$\checkmark 1$ Hughes CM, McElnay JC, Fleming GF: Benefits and risks of self medication. Drug Saf 2001;24:1027-1037.

$>2$ Porteous T, Bond C, Hannaford P, Sinclair H: How and why are non-prescription analgesics used in Scotland? Fam Pract 2005;22:78-85.

3 World Health Organization: The role of the pharmacist in self-care and self-medication. Report of the 4th WHO Consultative Group on the role of the pharmacist in health care system 1998. http://www.who.int/medicines/ library/dap/who-dap-98-13/who-dap-98-13. pdf.

$\checkmark 4$ Geissler PW, Nokes K, Prince RJ, Achieng RO, Aagaard-Hansen J, Ouma JH: Children and medicines: self-treatment of common illnesses among Luo school children in western Kenya. Soc Sci Med 2000;50:1771-1783.

$\checkmark 5$ Kiyingi KS, Lauwo JAK: Drugs in home: danger and waste. World Health Forum 1993; 14: 381-384.

6 Clavinjo HA: Self-medication during pregnancy. World Health Forum 1995; 16:403-404.
7 World Health Organization: Report of the WHO Expert Committee on National Drug Policies 1995. http://www.who.int/medicines/ library/dap/who-dap-95-9/who-dap-95.9. shtml.

8 Kafle KK, Gartulla RP: Self-medication and its impact on essential drugs schemes in Nepal: a sociocultural research project 1993. http:// www.who.int/medicines/library/dap/whodap-93-10/who-dap-93-10.shtml.

$>9$ Montastruc JL, Bagheri H, Geraud T, Lapeyre MM: Pharmacovigilance of self-medication. Therapie 1997;52:105-110.

10 Hebeeb GE, Gearhart JG: Common patient symptoms: patterns of self-treatment and prevention. J Miss State Med Assoc 1993;34:179_ 181.

-11 Martins AP, Miranda AC, Mendes Z, Soares MA, Ferreira P, Nogueira A: Self-medication in a Portuguese urban population: a prevalence study. Pharmacoepidemiol Drug Saf 2002;11: 409-414.

12 Shankar PR, Partha P, Shenoy N: Self-medication and non-doctor prescription practices in Pokhara valley, Western Nepal: a questionnaire-based study. BMC Family Practice 2002; $3: 17$.
13 Hughes CM: Monitoring self-medication. Expert Opin Drug Saf 2003;2:1-5.

$\checkmark 14$ Al Khaja KAJ, Handu SS, James H, Mathur VS, Sequeira RP: Assessing prescription writing skills of pre-clerkship medical students in a problem-based learning curriculum. Int $\mathrm{J}$ Clin Pharmacol Ther 2005;43:429-435.

15 Abahussain E, Matowe LK, Nicholls PJ: Selfreported medication use among adolescents in Kuwait. Med Princ Pract 2005;14:161-164.

16 Stewart MA: Effective physician-patient communication and health outcomes: a review. Can Med Assoc J 1996;152:1423-1433.

17 Obermeyer CM, Schulein M, Hardon A, Sievert LL, Price K, Santiago AC, Lazacano O, Kirumira EK, Neuman M: Gender and medication use: an exploratory, multi-site study. Women Health 2004;39:57-73.

18 Vedrana AV, Vladimir T, Zdravko L: Content of home pharmacies and self-medication practices in households of pharmacy and medical students in Zagreb, Croatia: findings in 2001 with a reference to 1977 . Croat Med J 2005;46: 74-80. 